\title{
JUSTUM ВELLUM КАК ФИЛОСОФСКАЯ ТРАДИЦИЯ МОРАЛЬНОГО ОГРАНИЧЕНИЯ ВоЙНЫ
}

\author{
И.А. Панафидин
}

\section{1. Введение: два значения термина justum bellum}

Латинское выражение justum bellum обычно переводят как «справедливая война» и связывают, прежде всего, с одноименной теорией, оформившейся во второй половине XX века. Эта теория представляет собой совокупность морально-правовых принципов jus ad bellum (справедливого или законного начала войны), принципов jus in bello (правомерного ведения войны), а в последнее время к ней предлагают включить и принципы jus post bellum (справедливого окончания войны).

Bсе перечисленные принципы, призванные разграничить справедливые и несправедливые войны, изложены в многочисленных научных статьях и монографиях, в которых активно обговариваются проблемы этики войны в целом или же моральности отдельных военных кампаний. Среди авторов таких исследований необходимо отметить Дж.Ф. Чайлдреса, П. Рамсея, М. Уолзера, О. О'Донована, Р. Филлипса.

Русскоязычному читателю основные положения теории справедливой войны известны, в частности, по переводам работы Х. Сисе [16] и коллективного труда «Нравственные ограничения войны» [11]. В большинстве исследований представителей данной теории принципы 
справедливой войны излагаются как абсолютно непроблематичные и очевидные, хотя на самом деле они таковыми не являются.

Второе значение выражения justum bellum связано с философской традицией справедливой войны как традицией морального ограничения войны, восходящей к античности. В рамках этой традиции осуществляется попытка проинтерпретировать идею справедливой войны, исходя из определенного понимания справедливости. Поскольку приверженцы и критики теории справедливой войны расходятся в понимании предиката «справедливый», с нашей точки зрения, необходимо рассмотреть аргументацию тех мыслителей прежних эпох, к которым постоянно апеллируют представители современной версии этой теории. Это позволит подвести под последнюю серьезное философское основание и перевести дискурс относительно идеи справедливой войны из идеологического в научное русло. Поэтому целъю данной статьи является классифицирование концепций справедливой войны, имевших место в истории философии, исходя из различного понимания справедливости.

Итак, если следовать философской традиции, «справедливая война» - это именно справедливая война. Определенный генезис социально-философской идеи справедливой войны связан не столько с трансформацией понятия войны, сколько с трансформацией понятия справедливости. Чтобы проиллюстрировать, как изменялось в истории философии представление о справедливой войне, на наш взгляд, необходимо рассмотреть различные подходы к пониманию справедливости.

Из всех возможных философских концепций справедливости нам наиболее предпочтительней и теоретически разработанной кажется концепция Аристотеля, аналитически классифицированная современным немецким философом Отфридом Хеффе. Поэтому именно ее мы возьмем за основу классифицирования концепций справедливой войны.

\section{2. Аналитическая классификация справедливости и идея справедливой войны}

Согласно Хеффе, в границах общего понятия справедливости Аристотель проводит различия, которые остаются актуальными и сегодня. Главное достижение античного классика состоит в открытии частной справедливости (в отличие от всеобщей справедливости как одной из главных добродетелей) [18, с. 29-30]. 
Обобщая способы применения Аристотелем термина «справедливость», Хеффе предложил достаточно интересную аналитическую классификацию, в соответствии с которой справедливость разделяется на «абстрактную» (справедливость как таковую) и справедливость в институтах. Последняя, в свою очередь, разделяется на политическую и неполитическую, а политическая - на справедливость по закону (позитивное право) и справедливость по природе (естественное право) $[18$, с. 33]. Что касается «абстрактной справедливости», то, согласно классификации Хеффе, она делится на всеобщую и частную разновидности справедливости, а последняя - на распределение, порядок и обмен.

Какие же из указанных аспектов справедливости принимались во внимание мыслителями, разрабатывающими свои концепции справедливой войны? Поскольку войны инициируются и проводятся политическими институтами, прежде всего государствами, то для обоснования идеи справедливой войны необходимо задействовать политическую справедливость как одну из разновидностей справедливости в институтах. Кроме того, поскольку войны ведутся среди прочего за распределение материальных благ, т. е. имеют своей причиной экономические мотивы, то следует принять во внимание и такую разновидность абстрактной справедливости как дистрибутивная справедливость.

Аналитическая классификация справедливости Хеффе, на наш взгляд, может быть расширена за счет выделения разновидностей дистрибутивной справедливости. Так, например, П.Е. Матвеев предлагает различать следующие виды дистрибутивной справедливости: элитарная, демократическая, эгалитарная, справедливость как честность Дж. Ролза.

Итак, в последующем изложении мы обоснуем тезис, что, опираясь на указанные аспекты понимания справедливости (справедливость по природе и распределительная справедливость), в истории философии были предложены, с одной стороны, различные варианты естественноправовой концепции справедливой войны, а с другой - такие разновидности дистрибутивных концепций справедливой войны, как элитарная, демократическая, эгалитарная и либеральная. Современная версия теории справедливой войны основывается, прежде всего, на естественно-правовой концепции, хотя и приобретает характер позитивноправовой концепции, поскольку многие выведенные из естественного права принципы справедливой войны сегодня образуют основу международного права. 


\section{3. Естественно-правовые концепции справедливой войны}

Естественно-правовая концепция справедливой войны впервые появляется в философской традиции Древнего Рима, в частности, в трудах М.Т. Цицерона. Опираясь на цицероновское понимание справедливой войны, эту традицию в дальнейшем продолжили А. Августин, $\Phi$. Аквинский и Г. Гроций.

Согласно Цицерону, «каждому виду живых существ природа даровала стремление защищаться, защищать свою жизнь, то есть свое тело, избегать всего того, что кажется вредоносным» [20, с.61]. Из этого тезиса он выводит обоснование естественно-правовой концепции справедливой войны: если природа дала возможность человеку обороняться, то самозащита является природным свойством. Поскольку человеческая жизнь является наивысшей ценностью, а ее целью и содержанием согласно природе является благо, то защищая себя, человек защищает и благо.

Важно отметить, что у Цицерона концепция справедливой войны основывалась не только на идее естественного права, но и на идее фециального (освященного богами) закона римского народа [20, с. 63]. По сути именно ему принадлежит первенство в формулировании некоторых принципов jus ad bellum («правого дела» и «добрых намерений») и jus in bello (приниципов соразмерности и различения). Так, Цицерон утверждает:

Ни одна война не может считаться справедливой, если она, не возвещена, не обьявлена, не начата из-за неисполненного требования возместить нанесенный ущерб [19, с. 65].

Как видно, здесь речь идет о следующих принципах начала справедливой войны:

(1) война должна быть провозглашена;

(2) война начинается из-за отказа возмещения ущерба;

(3) война проводится с целью защиты союзников [там же].

В трактате «Об обязанностях» мы можем найти и принципы jus in bello:

Что касается разрушения и разграбления городов, то надо строго следить за тем, чтобы не было допущено ни опрометчивости, ни жестокости. Долг великого мужа - среди потрясений карать виновных, но 
большинство людей щадить, при любых обстоятельствах оставаться верным справедливости и нравственной красоте [20, с. 79].

Итак, естественно-правовая концепция справедливой войны, обоснованная Цицероном, предусматривает ведение военных действий только при условии определения четких причин возникновения вооруженного конфликта, а также соблюдения условий его протекания с целью узаконить завоеванное и уменьшить возможные жертвы.

В эпоху средневековья естественно-правовая концепция справедливой войны была переосмыслена в рамках христианской философской мысли, провозглашающей источником естественного права Бога как некую трансцендентную силу. Исходя из платоновской концепции понимания идеи Блага, Августин вносит некоторые коррективы в экспликацию справедливости. Для него благо выступает телеологическим процессом, которому должна быть подчинена вся жизнь человека, а справедливость состоит в том, «чтобы воздать каждому то, что суть его». «Естественный порядок справедливости», согласно Августину, проявляется в том, что «душа подчиняется Богу, плоть - душе, а через это и плоть и душа-Богу» [2, с. 325].

Августин, как известно, проводит различение между градом Божьим и градом земным, утверждая, что подлинная справедливость относится только к первому. Земной град представляет собой совокупность грешников, которые своей деятельностью умножают зло и несправедливость. Война, согласно Августину, «дело человеческое, причем дело нежелательное» $[1$, с. 295]. В то же время он, в отличие от пацифистски настроенных апологетов, различал справедливые и несправедливые войны и обосновывал необходимость для христиан принимать участие в войне, если она ведется от имени церкви как проявления Божьего града в земном мире. Вслед за Цицероном, Августин также зачисляет потребность защищать себя к природным потребностям человека в условиях функционирования несправедливого града земного [2, с. 333-334].

Жан Флори утверждает, что именно Августин изменил взгляды христиан на природу войны.

Эволюцию общехристианского менталитета в отношении войны хорошо выражает святой Августин, развивающий в своих работах двоякую идею: с одной стороны, обязательного неприятия несправедливой войны, этого бича человечества, но с другой - признания справедливой войны $[17$, с. 39].

Такая диалектическая диспозиция сразу же приобрела форму идеологии, которую Флори называет «идеологией меча»: «война бывает 
справедливой, и христианин может без угрызений совести участвовать в ней». Эта идеология четко выражает структуру средневекового общества: «Одним надлежит бороться молитвой против демонов, в то время как другим сражаться оружием против варваров» [там же]. Обосновав саму возможность войны в качестве справедливой, Августин все же не разработал целостной теории справедливой войны в рамках христианской философской мысли. Формирование средневековой версии естественно-правовой концепции справедливой войны теоретически завершил Фома Аквинский.

Аквинский исходил из различения трех видов права: (1) вечного (божественного), (2) естественного и (3) позитивного. Вечное право ведет человека к всеобщему благу, сущность которого проявляется в человеческом разуме, оно же является источником естественного права и «представляет собой совокупность правил вечного права, привившегося в человеческих умах, и отраженного в них» $[6$, с. 125-126]. Применение принципов естественного права в общественной жизни образует фундамент для позитивного права.

Подобно Цицерону и Августину, Фома Аквинский следует аристотелевской традиции понимания блага и выводит идею справедливости из главной добродетели, называя ее «правосудностью». Исходя из понимания справедливости как «должного отношения среди равных» [3, с. 148], у Аквинского естественно-правовая концепция справедливой войны приобретает черты фундаментального учения с четко сформированными критериями.

Согласно Фоме Аквинскому, мир является божественным предписанием и актом добродетели, которым может противостоять лишь грех. Поскольку война противостоит миру, следовательно, она является греховной по своей сути. Однако, вслед за Августином, Фома Аквинский утверждает, что войну начинают ради мира и воины в состоянии боевых действий должны быть в первую очередь миротворцами, которые, побеждая врагов, тем самым приводят их к миру. Поэтому, нужны такие условия для начала боевых действий, которые не вызывали бы никаких сомнений относительно идеи блага, ради которой и начинают войну. Такими критериями у Аквинского выступают:

(1) «полномочность правителя, по приказу которого ведется война»;

(2) «справедливая причина», то есть самозащита или месть за отказ уплаты за нанесенный ущерб; 
(3) «справедливое намерение», которое «имеет своей целью утверждение добра или предотвращение зла» [4, с. 497-505].

Таким образом, согласно Фоме Аквинскому, при наличии этих трех необходимых условий справедливая война не является грехом, поскольку те, кто ее проводят, не противостоят миру, а если и противостоят, то только греховному, а значит ненастоящему, миру.

В эпоху раннего Нового времени философская традиция естественного и позитивного права вследствие процесса секуляризации сознания, формирования национальных государств, зарождения просветительских идей значительно трансформируется. Обобщив учения Аристотеля, Цицерона, Августина и Аквинского, Гуго Гроций сформулировал ключевые принципы современной теории справедливой войны и создал основы рационалистической версии общественного договора [7, с. 227$]$.

Особенно удачным, на наш взгляд, является его определение войны как «состояния борьбы силой как таковое». Это состояние может быть вызванным каким-либо спором между государствами, частными лицами, а также лицами, имеющими определенные права - «лицами знатного происхождения» или «свободными гражданами в республиках» [8, с.67-68]. Все возможные войны Гроций разделяет на публичные, частные и смешанные. Публичная война проводится государственной властью, частная - частными лицами, смешанная - как частными, так и государственными лицами. Подобная классификация позволяет Гроцию более подробно рассмотреть сущность войны и связать ее с наивысшей моральной ценностью - справедливостью.

Если целью войны выступает «сохранение неприкосновенности жизни и членов тела, сохранение и приобретение вещей, полезных для жизни», то такая цель есть благою, поскольку она вытекает из природы человека. Применение насилия запрещается только тогда, когда «нарушается чужое право» [8, с. 84-85]. Также как и у Цицерона, согласно Гроцию, справедливая война, прежде чем начаться, должна быть провозглашена. А сама процедура оглашения может быть условной, безусловной и простой. Условное оглашение войны предусматривает требование возмещения врагом захваченных им вещей, причем, если он это требование удовлетворяет, война может и не начаться. Безусловное оглашение войны проводится при условии уже начавшихся боевых действий или наказания за преступление, требующего возмездия. Простое оглашение войны применяется при обоюдном провозглашении войны [8, с.610-611]. Итак, справедливой Гроций называет «тор- 
жественную войну» (провозглашенную), которая только и является «законной». Кроме того, при проведении войны должны быть строго соблюдены два условия: (1) ее субъектом может быть только государственная власть, (2) соблюдение определенных обрядов и церемоний $[8$, c. 123$]$.

\section{4. Дистрибутивные концепции справедливой войны}

Кроме естественно-правовой концепции справедливой войны, как уже отмечалось, в истории философии были разработаны различные версии дистрибутивной концепции, в частности элитарная (Платон), демократическая (Ж.-Ж. Руссо), эгалитарная (марксизм) и либеральная (Дж. Ролз). Элитарная концепция справедливой войны как производная от идеи элитарной дистрибутивной справедливости связана, прежде всего, с концепцией идеального государства Платона. Согласно Платону, справедливость является главной добродетелью государства, а сама сущность этой идеи вытекает из божественной идеи Блага. Идея Блага возглавляет все остальные идеи, выступающие прообразом мира чувственных вещей, а потому справедливость является результатом действия космических законов. Однако реализация такой справедливости как добродетели государства возможна при условии, что это государство будет справедливо устроено, т. е. когда каждый человек будет заниматься своим делом в соответствии с присущим ему типом души (разумная, страстная, вожделеющая). Если такой порядок нарушается, это, согласно Платону, может нанести огромный вред и даже привести к гибели государства [12, с. 217-226]. Каждому из трех сословий (правители, стражи, ремесленники и земледельцы) в платоновском государстве соответствует своя добродетель: мудрость, мужество и рассудительность. В совокупности они обеспечивают функционирование главной добродетели - справедливости.

Как отмечает П.Е. Матвеев, концепцию справедливости, обосновываемую Платоном в диалоге «Государство», можно назвать элитарной дистрибутивной [10, с. 62]. Распределение общественных благ осуществляется согласно принципу доминирования в человеке природных качеств. Таким образом, человек, который может быть ремесленником и не имеет таланта воина, никогда не станет представителем высшего сословия, если у него нет мужества. Он обречен на тяжелый труд, в силу господства над ним души, желающей различных удовольствий. 
Воины, которые имеют аффективную душу, но не имеют разума, также не могут перейти в наивысшее сословие философов-правителей. Умение управлять доступно лишь лучшим воинам, которые владеют разумной частью души.

Каким же образом осуществляется разделение благ согласно принципу элитарности? Общеизвестным является тот факт, что Платон нивелирует роль частной собственности в идеальном государстве, владеть ею разрешается только низшему сословию - ремесленникам и земледельцам. Однако право на ее разделение доступно только наивысшему сословию - элите общества - философам. Именно они и определяют, кто, чем и как будет владеть. Такая дистрибутивная справедливость должна эксплицироваться как элитарная, поскольку элита, а не общество определяет разделение благ.

Более того, элитарное распределение благ касается и сферы внешней политики. Согласно платоновской концепции идеального государства, война начинается именно тогда, когда государству необходимы излишние земельные ресурсы: речь идет о пашнях и пастбищах, которые жизненно важны для обеспечения достатка не только граждан, но и гетер, поэтов, кулинаров, цирюльников. Деятельность последних обеспечивает удовлетворение страстей эллинов как граждан. Эти наслаждения роскошью, ласками куртизанок и обильными пирами и являются тем фактором, который, по мнению Платона, облагораживает природное состояние человека «цивилизацией», что и является главным источником всех бед человечества, связанных с войной $[12$, c. 150-151].

Используя понятие «справедливая война», Платон применяет его только к характеристике вооруженного конфликта между эллинами и варварами, в то же время, провозглашая губительность гражданской войны («раздора») между самими греками. В «Государстве» он определяет эллинов как «близких друг другу людей», которые «состоят между собой в родстве», тогда как варваров называет «иноземцами и чужаками», являющимися «по самой своей природе врагами» [12, с. 271]. Следовательно, элитарная справедливая война - это природный закон эллинов, у которых существует божественная цель облагораживание мира.

В отличие от Платона, Ж.-Ж. Руссо разрабатывает демократическую концепцию дистрибутивной справедливости. Руссо рассматривает справедливость, продолжая традицию естественного права:

То, что соответствует благу как порядку, является таковым по природе вещей и не зависит от соглашений между людьми. Всякая спра- 
ведливость - от Бога, он Один - ее источник; но если бы мы могли получать ее с такой высоты, мы бы не нуждались ни в правительстве, ни в законах $[15$, с. 176].

Согласно Руссо, существует также и общая справедливость, проистекающая только из разума, но эта справедливость, чтобы быть принятой нами, должна быть взаимной. Поэтому она должна опираться на наибольшее благо для всех, сводящееся к свободе и равенству. Свобода предусматривает наличие в человеке достоинства, естественных прав и его обязанностей [15, с. 156]. Кроме естественной свободы, Руссо говорит и о «гражданской свободе», приобретаемой человеком при заключении общественного договора - свободе следования закону, установленному человеком ради самого себя [15, с. 165]. Что касается равенства, то оно является результатом общественного договора (акта общей воли), позволяющего суверену рассматривать нацию в качестве единого целого. Итак, согласно Руссо, только общественный договор гарантирует общую справедливость, которая по своему содержанию является дистрибутивной демократической справедливостью, т. е. связана с провозглашением получения максимума благ каждым членом общества.

Переходя к рассмотрению войны, Руссо утверждает, что она является актом политическим, но причинами возникновения войны, как и Платон, он считает экономические:

Если земли слишком много, то охрана ее тягостна, обработка - недостаточна, продуктов - избыток; в этом причина будущих оборонительных войн. Если же земли недостаточно, то Государство, дабы сие восполнить, оказывается в полнейшей зависимости от своих соседей; в этом - причина будущих наступательных войн [15, с. 186].

Следует отметить, что у Руссо отсутствует теоретическое обоснование целостной концепции справедливой войны, однако обосновываемые им требования к проведению военных действий в целом можно обозначить как демократическую концепцию справедливой войны. Согласно Руссо, война может быть справедливой при условии, что она проводится государством, образованным в результате общественного договора:

Даже в разгаре войны справедливый государь, захватывая во вражеской стране все, что принадлежит народу в целом, при этом уважает личность и имущество частных лиц; он уважает права, на которых основаны его собственные [там же].

В результате исчезает сама суть войны, поскольку экономические причины войн нивелируются особенным статусом врага. Если врага 
уважают, а его имущество неприкосновенно, то война приобретает характер рыцарского поединка. Враг только тогда является соперником, пока держит в руках оружие [там же].

Рассмотренная концепция демократической справедливой войны Руссо включает в себя следующие критерии:

(1) война должна быть оглашена:

Объявление войны служит предупреждением не столько Державам, сколько их подданным. Чужой, будь то король, частный человек или народ, который грабит, убивает или держит в неволе подданных, не объявляя войны государю, - это не враг, а разбойник [там же].

Если война оглашена, она проводится на законных основаниях;

(2) врага необходимо «уважать», ведь он является защитником своей отчизны, и даже после поражения является человеком, который имеет все права, в том числе и на частную собственность;

(3) право завоевателя является только одномоментным актом, оно основывается только на силе, следовательно, не имеет статуса права как такового.

Если в Новое время одной из ведущих социально-философских традиций была традиция естественного права, то в рамках марксизма она была подвергнута критике в связи с обоснованием эгалитарной концепции справедливости. Так, например, согласно Ф. Энгельсу:

Справедливость всегда представляет собой лишь идеологизированное, вознесенное на небеса выражение существующих экономических отношений либо с их консервативной, либо с их революционной стороны [21, с. 273].

Что касается позитивного права, согласно историческому материализму, оно относится к надстройке, которая представляет собой всего лишь отображение существующих в обществе экономических отношений. Поэтому разрешение всех человеческих проблем связывается в марксизме с изменением производственных отношений.

Следует отметить, что и в учениях основателей марксизма, и у их последователей отсутствует сколь-нибудь разработанное как морально-этическое учение в целом, так и учение о справедливости в частности. Однако сам принцип построения коммунистического общества предусматривает такое разделение экономических благ, который можно охарактеризовать как принцип эгалитарной дистрибутив- 
ной справедливости, требующей, «чтобы все члены общества получили равные блага, т. е. чтобы разделение благ совершалось по принципу воздающей справедливости» [10, с. 57]. П.Е. Матвеев утверждает, что в марксизме справедливость оценивается как высшая по рангу ценность, в жертву которой можно принести другие ценности, в том числе свободу, достоинство, счастье людей. Именно в этом состоит один из главных моральных недостатков эгалитарной концепции, поскольку тут нарушается объективная иерархия, присуща системе моральных ценностей [9, с. 57].

Опираясь на эгалитарное понимание справедливости, представленное в трудах К. Маркса и $Ф$. Энгельса, представители советского марксизма обосновали свое понимание справедливой войны как оборонной, в отличие от войны наступательной как несправедливой и незаконной. Критерием справедливости здесь выступает фактор эксплуатируемости, т. е. справедливой считается та война, которая ведется против эксплуататорских, и даже рабовладельческих (колониальных), государств [9, с. 417-418]. Итак, в рамках эгалитарной концепции справедливой войны справедливой провозглашается война, которая ведется с целью «защиты угнетенных стран» по классовому признаку и даже превентивного удара или интервенцию в форме печально известной «мировой социалистической революции».

Оригинальное понимание справедливой войны обосновал в своей концепции справедливости как честности Джон Ролз. Согласно Ролзу, «справедливость является первой добродетелью общественных институтов» $[14$, с. 19], именно она выступает тем фактором, который может обеспечить эффективность какого-либо государственного устройства. Главным принципом, на котором базируется благосостояние общества, выступает неприкосновенность каждой личности, которая не может быть нарушена, даже для благосостояния целого общества. Таким образом, справедливым является то общество, где свобода каждого гражданина неприкосновенна $[14$, с. 27$]$.

Дистрибутивная концепция справедливости Ролза базируется на двух принципах:

(1) «каждое лицо, принимающее участие в какой-либо практике, или находящееся в сфере ее воздействия, имеет равное право на наиболее обширную свободу, совместимую с такой же свободой для всех остальных»;

(2) «неравенство допустимо только в том случае, если разумно ожидать, что оно будет выгодно для всех и при условии, что то об- 
щественное положение и те должности, с которыми оно связано, или из которых оно вытекает, являются доступными для всех» $[13$, c. 36$]$.

Свобода индивида является настолько полной, что он может даже отказаться от участия в несправедливой войне. Но в этом отказе он должен апеллировать к конкретным принципам, например:

(1) в справедливой войне строго недопустимыми являются определенные формы насилия, более того, там, где jus ad bellum сомнительны и неопределенны, ограничения на средства ее проведения стают еще более суровыми;

(2) действия, допустимые в справедливой войне, когда они необходимы, могут категорически исключаться в более сомнительной ситуации;

(3) целью справедливой войны является справедливый мир, следовательно, использованные средства не должны разрушать возможность достижения мира или поощрять пренебрежение к человеческой жизни, поскольку они могут поставить под угрозу не только нашу безопасность, но и безопасность человечества в будущем [14, с. 517-520].

Таким образом, концепция справедливой войны Ролза, которую можно обозначить как либеральную, предусматривает определенную трансформацию культуры войны в культуру мира на основе признания права свободного выбора индивида, принимать ли участие в той или иной войне, т. е. самостоятельно определять, является ли война справедливой.

\section{5. Справедливая война - прежде всего война}

Проанализированные естественно-правовые и дистрибутивные концепции справедливой войны, имеющие место в истории философской мысли, демонстрируют попытку ее авторов обосновать необходимость морального ограничения войны. В целом оценивая войну как зло, отчасти неизбежное, они доказывали, что в некоторых случаях война является относительным добром, а именно когда при вступлении в войну и при ее проведении соблюдаются выведенные из того или иного понимания справедливости правила, т. е. когда ее проявления морально 
ограничены. Делая упор на интерпретации предиката «справедливая» и тем самым обогащая философскую традицию морального ограничения войны, авторы многочисленных концепций справедливой войны мало уделяли внимания анализу второй составляющей указанной идеи - войне. Как следствие, достаточно сомнительным, с нашей точки зрения, выглядит один из главных выводов теории справедливой войны, что целью такой войны всегда является мир. Справедливая война - это не только справедливая война, но именно война, т. е. в первую очередь она является войной, а затем уже справедливой. Любая война, в том числе справедливая, по своей сути является насилием, поэтому попытки ограничения насилия, осуществленные в философской традиции справедливой войны, необходимо рассматривать как позитивное явление, однако не приводящее к его окончательному устранению. Идея морального ограничения войны - только первый этап на пути к ее преодолению.

Латинское выражение justum bellum можно переводить не только как «справедливая война», но и «оправданная война». Одним из наиболее важных способов морального оправдания войны служит тезис, согласно которому ее целью является установление мира путем возобновления справедливости. В частности об этом говорил Г. Гроций: «Во время войны необходимо всегда стремиться к миру» [8, с. 824]. Однако апеллируя к идее морально оправданной войны, т. е. морально оправданного насилия, мы никогда не придем к прочному миру. Ведь даже согласившись с условиями мира, продиктованными победителем, побежденный рано или поздно захочет снова вступить в войну, или же победитель в новых условиях найдет «справедливые» причины начать новую войну.

Анализируя метанормативное содержание принципов справедливой войны, Р.Г. Апресян обращает внимание на то, что исторически они «были сформулированы как требования к суверену». Однако в современных условиях принципы справедливой войны выступают не только «критериями для принятия властных решений», но и «превратились также в элемент публичного дискурса о войне» [5, с. 62]. Поэтому участники военного противостояния нередко используют их для прикрытия собственной политической демагогии, умело манипулируя массовым сознанием. В результате несправедливые причины начала войны, преподнесенные для нападающих в качестве справедливых, могут спровоцировать или адекватный ответ тех, кто также считает, что вступает в справедливую войну, или в случае, если противник достаточно силен, установку на основательную подготовку к такому аде- 
кватному ответу в будущем.

В связи с этим, как нам представляется, дальнейшее развитие философской традиции справедливой войны должно проходить в направлении трансформации понятия войны. По-разному понимая справедливость, приверженцы и естественно-правовых, и дистрибутивных концепций справедливой войны в целом исходили из общего понимания войны как средства политики, хотя и крайнего, иногда вынужденного. В данном аспекте их позиция совпадает с позицией политического реализма, опирающегося на классическое понимание войны, сформулированное К. фон Клаузевицем. Если же война рассматривается в качестве инструмента политики, то она имеет именно политическую цель - навязать свою волю противнику. Следовательно, окончание такой войны приведет к установлению «мира силы» (Р. Арон), который не является миром в полном смысле этого слова. Установление последнего возможно только при условии пересмотра классической точки зрения на соотношение войны и политики, когда политике будет запрещено использовать войну в качестве своего средства.

\section{Литература}

[1] Августин Блаженный. Творения в 4 т.-СПб.: Алетейя ; К.: УЦИММ-Пресс, 1998. - Т. 3. О Граде Божьем.

[2] Августин Блаженный. Творения в 4 т.-СПб.: Алетейя ; К.: УЦИММ-Пресс, 1998. - Т. 4. О Граде Божьем.

[3] Аквинский Ф. Сумма теологии. Ч. II - I. Вопросы 49-89. - К. : Ника-Центр, 2008.

[4] Аквинский Ф. Сумма теологии. Ч. II - II. Вопросы 1-46. - К. : Ника-Центр, 2011.

[5] Апресян Р.Г. Метанормативное содержание принципов справедливой войны // Полис. - 2002. - № 3. - С. 57-71.

[6] Боргош Ю. Фома Аквинский. - М. : Мысль, 1975.

[7] Волков С.Ю. Развитие доктрины справедливой войны в эпоху раннего Нового Времени // Вестник Нижегородского университета им. Н.И. Лобачевского. Серия Международные отношения. Политология. Религиоведение. - 2009. - № 3. - С. 227-233. 
[8] Грочий Г. О праве войны и мира. Три книги, в которых объясняются естественное право и право народов, а также принципы публичного права. - М. : Ладомир, 1994.

[9] Ленин В.И. Социализм и война // В.И. Ленин о войне, армии и военной науке. - Сборник в 2-х т. - М. : Военное издательство министерства обороны СССР, 1958. - Т. 1.

[10] Матвеев П.Е. Этика. Основы хозяйственной этики: Курс лекций. Ч. 2. - Владимир: Владим. гос. ун-т., 2003.

[11] Нравственные ограничения войны: Проблемы и примеры. - М. : Гардарики, 2002.

[12] Платон. Государство // Платон. Диалоги. Книга вторая. - М. : Эксмо, 2008. - С. 89-454.

[13] Ролз Дж. Справедливость как честность // Логос. - 2006. - № 1 (52). - С. 35-60.

[14] Ролз Дж. Теорія справедливості. - К. : Вид-во Соломії Павличко «Основи», 2001.

[15] Руссо Ж.-ЖК. Об Общественном договоре, или Принципы политического Права. - М. : Наука, 1969. - С. 151-256.

[16] Cuce X. Справедливая война? О военной мощи, этике и идеалах. М. : Весь Мир, 2007.

[17] Флори Ж. Идеология меча. Предыстория рыцарства. - СПб. : Евразия, 1999.

[18] Хеффе О. Справедливость: Философское введение. - М. : Праксис, 2007.

[19] Цицерон. О государстве // Цицерон. Диалоги. О государстве. О законах. - М. : Наука, 1966. - C. 7-88.

[20] Цицерон. Об обязанностях // Цицерон. О старости. О дружбе. Об обязанностях. - М. : Наука, 1974. - С. 58-156.

[21] Энгельс Ф. К жилищному вопросу // Маркс К., Энгельс Ф. Собрание сочинений. - М. : Государственное издательство политической литературы, 1961. - Т. 18. - С. 203-284.

Надійшла до редакцї̈ 30 червня 2014 р. 